\title{
Putative Bioactive Conformations of Amide Linked Cyclic Myelin Basic Protein Peptide Analogues Associated with Experimental Autoimmune Encephalomyelitis
}

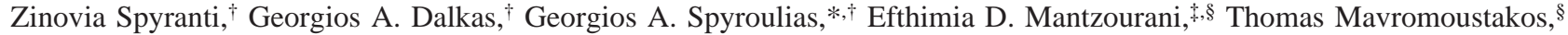 \\ Irene Friligou, ${ }^{\ddagger}$ John M. Matsoukas ${ }^{\ddagger}{ }^{\circ}$ and Theodore V. Tselios $*$ \\ Departments of Pharmacy and Chemistry, University of Patras, GR-26504 Patras, Greece, and Institute of Organic and Pharmaceutical \\ Chemistry, National Hellenic Research Foundation, GR-11635 Athens, Greece
}

Received June 28, 2007

\begin{abstract}
The solution models of cyclo(87-99) $\mathrm{MBP}_{87-99}$, cyclo(87-99) [Ala ${ }^{91,96}$ ] $\mathrm{MBP}_{87-99}$, and cyclo(87-99) [Arg ${ }^{91}$, $\mathrm{Ala}^{96}{ }^{9} \mathrm{MBP}_{87-99}$ have been determined through 2D NMR spectroscopy in DMSO- $d_{6}$. Chemical shift analysis has been performed in an attempt to elucidate structural changes occurring upon substitution of native residues. NMR-derived geometrical constraints have been used in order to calculate high-resolution conformers of the above peptides. Conformational analysis of the three synthetic analogues show that the bioactivity, or the lack of it, may possibly be due to the distinct local structure observed and the subsequent differences in the overall topology and exposed area after binding with Major Histocompatibility Complex II (MHC II). It is believed that an overall larger solvent accessible area blocks the approach and binding of the T-cell receptor (TCR) on the altered peptide ligand (APL) - MHC complex, whereas more compact structures do not occlude weak interactions with an approaching TCR and can cause Experimental Autoimmune Encephalomyelitis (EAE) antagonism. A pharmacophore model based on the structural data has been generated.
\end{abstract}

\section{Introduction}

Multiple Sclerosis $(\mathrm{MS})^{a}$ is a progressive demyelinating disease of the Central Nervous System (CNS) in which a coordinated attack of the immune system takes place against the myelin sheath. ${ }^{1}$ Although the antigenic components of Myelin in MS have not been identified with certainty yet, myelin Basic Protein (MBP) is believed to be one of the main candidate autoantigens, and $\mathrm{MBP}_{87-99}$ is encephalitogenic in EAE, the best studied animal model for MS. ${ }^{2-6}$

Analogues of immunodominant epitopes of these proteins (Altered Peptide Ligands, APLs) can induce or suppress EAE in rodents through the formation of a trimolecular complex between the MHC-peptide (antigen) - TCR and the triggering of different immunological responses. Antagonism requires an APL to induce biochemical activity, which is inhibitory over the agonist-delivered signals.

A two-step mechanism for TCR recognition has been proposed. $^{7}$ Initial TCR-MHC interactions guide the TCR to its ligand in an orientation that positions the rigid CDR1 and CDR2 loops mainly over the MHC. This is followed by a final folding of the two highly flexible CDR3 loops ${ }^{8}$ of the TCR over the peptide. T-cell activation is triggered only on the formation of stable peptide contacts, and APLs induce biochemical activity which is inhibitory over the agonist-delivered signals. Thus, the TCR may scan MHC molecules using a "lock

* Corresponding authors. (G.A.S.) Tel.: 0030-2610-969950 (office), -951 and -952 (lab). Fax: 0030-2610-969950. E-mail: G.A.Spyroulias@upatras.gr. (T.V.T.) Tel.: 0030-2610-997905. Fax: 0030-2610-997180. E-mail: ttselios@upatras.gr.

Department of Pharmacy, University of Patras.

$\doteqdot$ Department of Chemistry, University of Patras.

$\S$ National Hellenic Research Foundation.

a Abbreviations: MS, multiple sclerosis; CNS, central nervous system; TCR, T-cell receptor; APL, altered peptide ligand; MHC, major histocompatibility complex; HLA, human leukocyte antigens; EAE, experimental autoimmune encephalomyelitis; MBP, myelin basic protein; MD, molecular dynamics; DYANA, dynamic algorithm for NMR applications; REM, restrained energy minimization. and key" type of binding with its CDR1 and CDR2 loops, followed by an induced fit of its CDR3 loops over the peptide. ${ }^{9}$

X-ray studies have shown that the TCR from human autoimmune disease binds to the peptide-HLA-DR2b complex with an off-center mechanism, which positions the CDR3 loops of the TCR over residues His ${ }^{88}$ and $\mathrm{Phe}^{89}$ of the N-terminus of the $\mathrm{MBP}_{85-98}$ epitope. ${ }^{10}$ It is one of the best characterized TCRs from a human autoimmune disease, and this aberrant binding mode provides a possible explanation for the fact that in MS autoreactive T-cells escape deletion in the thymus and attack self-myelin. Similarly, the trimolecular complex of TCRpeptide-HLA-DR $2 \mathrm{a}^{11}$ reveals that the TCR primarily recognizes the N-terminal portion of MBP peptide too.

A promising strategy in the treatment of MS has been the rational design of APLs, which inactivate autoreactive specific T-cells. These APLs could bind with high affinity with MHC and compete for recognition of self-antigens at the antigen presentation, without activating disease-causing T-cells. Indeed, linear APLs [ $\left.\mathrm{Arg}^{91}, \mathrm{Ala}^{96}\right] \mathrm{MBP}_{87-99}$ and $\left[\mathrm{Ala}^{91,96}\right] \mathrm{MBP}_{87-99}$, which have critical TCR substitutions, have been shown to inhibit EAE induced by the guinea pig $\mathrm{MBP}_{74-85}$ epitope in Lewis rats. ${ }^{12}$ The use of linear peptides in therapeutic protocols, though, is limited because of their proteolytic degradation.

A new strategy is to synthesize a more hydrolytically stable molecule, e.g., a cyclic peptide or a peptidomimetic that retains the desired biological activity. In our previous studies based on the immunodominant human $\mathrm{MBP}_{87-99}$ epitope, two EAE antagonist cyclic analogues cyclo(87-99) $\left[\mathrm{Arg}^{91}, \mathrm{Ala}^{96}\right] \mathrm{MBP}_{87-99}$ and cyclo(87-99) [Ala $\left.{ }^{91,96}\right] \mathrm{MBP}_{87-99}{ }^{12,13}$ have been designed and synthesized. These molecules are as active against EAE induced by guinea pig $\mathrm{MBP}_{72-85}$ epitope as their linear counterparts, but they present enhanced stability. Acute monophasic EAE was developed in Lewis rats with guinea pig $\mathrm{MBP}_{72-85}$ alone, while EAE development was completely prevented by the co-administration of cyclo(87-99) [ $\left.\mathrm{Arg}^{91}, \mathrm{Ala}^{96}\right] \mathrm{MBP}_{87-99}$ and cyclo(87-99) $\left[\mathrm{Ala}^{91,96}\right] \mathrm{MBP}_{87-99}{ }^{14}$. Tissue samples from 

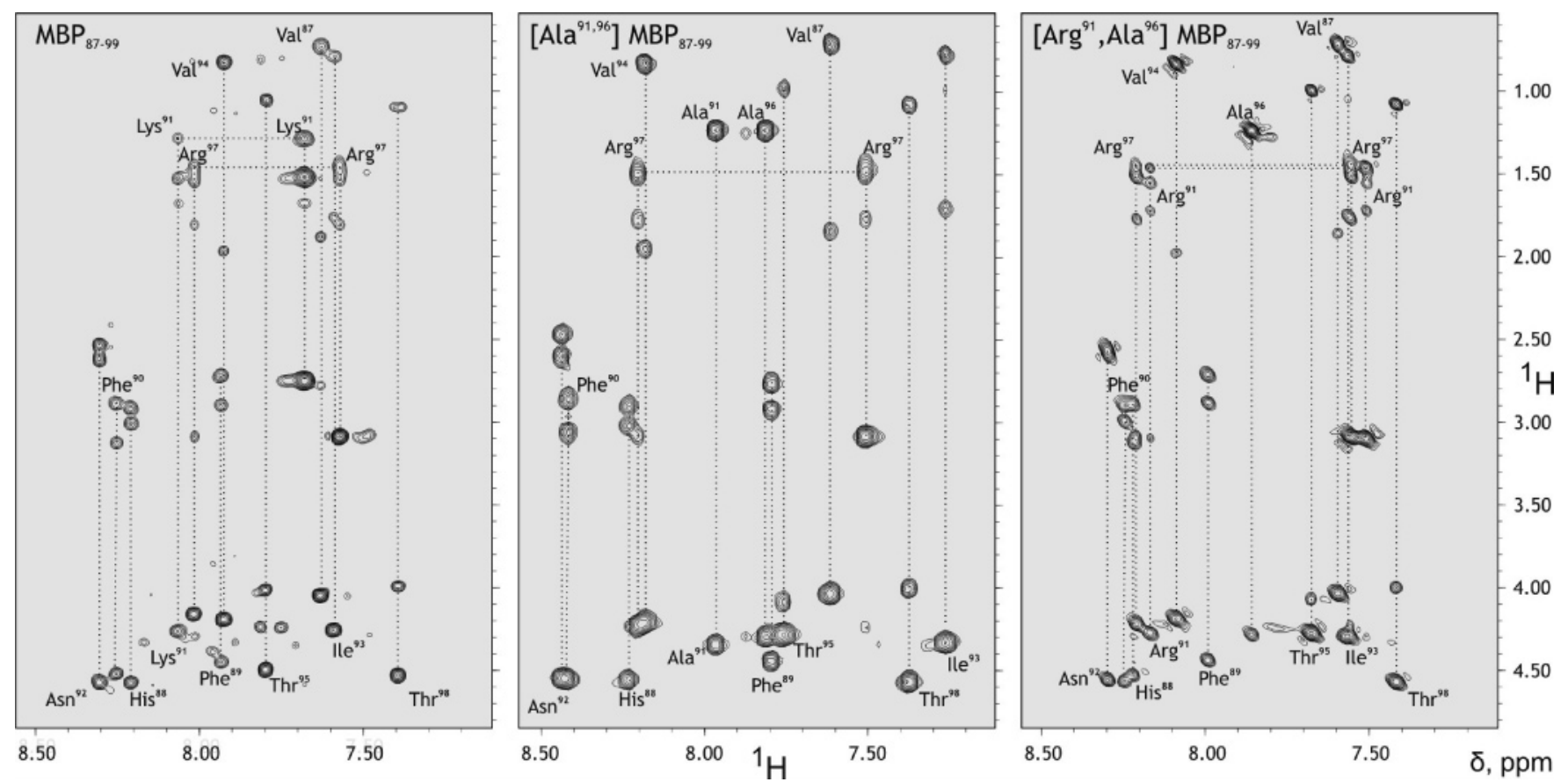

Figure 1. $2 \mathrm{D}{ }^{1} \mathrm{H}-{ }^{-1} \mathrm{H}$ TOCSY 600 and $700 \mathrm{MHz}$ NMR of cyclo(87-99) $\mathrm{MBP}_{87-99}$ (left), cyclo(87-99) [Ala ${ }^{91,96}$ ] MBP $87-99$ (middle), and cyclo(87-99) $\left[\mathrm{Arg}^{91}, \mathrm{Ala}^{96}\right] \mathrm{MBP}_{87-99}$ (right) recorded in DMSO- $d_{6}$ at $298 \mathrm{~K}$.

Lewis rats injected with $\mathrm{MBP}_{72-85}$ in complete adjuvant showed mononuclear cells around small vessels of the spinal cord. On the other hand, no inflammation was observed in any spinal cord sample from the Lewis rats immunized with cyclo(8799) $\left[\mathrm{Arg}^{91}, \mathrm{Ala}^{96}\right] \mathrm{MBP}_{87-99}$ and cyclo(87-99) [Ala ${ }^{91,96}$ ] $\mathrm{MBP}_{87-99}$ alone or co-injected with agonist $\mathrm{MBP}_{72-85}$ and antagonist APLs. ${ }^{14}$ The cyclic peptides were found to be more stable to lysozymal enzymes and Cathepsin B, D, and $\mathrm{H}$, compared to their linear counterparts. Moreover, cyclo(87-99) [Arg ${ }^{91}, \mathrm{Ala}^{96}$ ] $\mathrm{MBP}_{87-99}$ and cyclo(87-99) $\mathrm{MBP}_{87-99}$ were found to decrease the $\mathrm{Th} 2 / \mathrm{Th} 1$ ratio in peripheral blood mononuclear cells (PBMC) from MS patients and bound with comparable affinity to HLA-DR4. ${ }^{12}$ Cyclo(87-99) MBP $_{87-99}$ only induced weak EAE clinical signs in Lewis rats (clinical score 1) and affected T-cell (CD4+ T-cell line derived from an MS patient) proliferation. ${ }^{12}$ The antagonist cyclic peptide, cyclo(87-99) [ $\left.\mathrm{Arg}^{91}, \mathrm{Ala}^{96}\right] \mathrm{MBP}_{87-99}$, inhibited proliferation of the in vitro generated $\mathrm{CD} 4+\mathrm{T}$-cell clone (specific for $\left.\mathrm{MBP}_{87-99}\right)^{12}$

In this study, our goal is to examine the mean conformation of the APLs cyclo(87-99) $\mathrm{MBP}_{87-99}$, cyclo(87-99) [Ala ${ }^{91,96}$ ] $\mathrm{MBP}_{87-99}$, and cyclo(87-99) [ $\left.\mathrm{Arg}^{91}, \mathrm{Ala}^{96}\right] \mathrm{MBP}_{87-99}$, identify common features that comprise a structural motif, and hence derive conclusions relevant to the physicochemical and structural properties required for biological activity. A detailed conformational analysis of these potent cyclic agonist and antagonist peptide analogues could lead to rational designed peptidomimetics or non-peptide mimetics.

Within this scope, the following study focuses on the conformational analysis of the cyclic APLs. Experimental 2D NMR spectroscopic methods and restrained molecular dynamics simulation have been applied in order to obtain the mean structures in solution. The obtained results show that the two antagonist cyclic APLs form a bend in the middle segment of their sequence, leading to structures that are more compact, with a smaller solvent accessible area. Thus, they do not occlude weak interactions with an approaching TCR and can cause EAE antagonism. In contrast, cyclo(87-99) $\mathrm{MBP}_{87-99}$ is more compact in the $\mathrm{NH}$ terminus of the molecule but presents an overall larger solvent accessible area.

\section{Results and Discussion}

A. Proton Assignment. TOCSY maps were first analyzed to assign the individual spin patterns of amino acids through scalar connectivities (Figure 1). Sequential, medium, and long range connectivities were identified from NOESY maps acquired with $\tau_{\mathrm{m}}=300 \mathrm{~ms}$. Chemical shift for the three peptides are reported in Tables $\mathrm{S} 1-\mathrm{S} 3$ in the Supporting Information.

A.1. Cyclo(87-99) MBP $_{87-99}$ (I). Numerous $\mathrm{HN}-\mathrm{HN}$ sequential connectivities are detected in the regions of $\mathrm{Val}^{87}$ $\mathrm{Thr}^{95}$ and $\mathrm{Arg}^{97}-\mathrm{Thr}^{98}$, while $\mathrm{H}_{\alpha}-\mathrm{HN}$ sequential connectivities are also identified between all residues, except prolines (Pro ${ }^{96}$ and $\mathrm{Pro}^{99}$ ) (Figure $2 \mathrm{~A}-\mathrm{C}$ ). $\mathrm{H}_{\beta}-\mathrm{HN}$ sequential connectivities are detected in peptide fragments including residues $\mathrm{Val}^{87}-\mathrm{Phe}^{89}$, $\mathrm{Phe}^{90}-\mathrm{Thr}^{95}$, and Pro ${ }^{96}-\mathrm{Thr}^{98}$. An $\mathrm{H}_{\alpha}-\mathrm{HN}$ of $(i, i+3)$ type connectivity between $\mathrm{Val}^{87}-\mathrm{Phe}^{90}$ and an $\mathrm{H}_{\alpha}-\mathrm{H}_{\beta}$ of $(i, i+4)$ type connectivity between residues $\mathrm{His}^{88}-\mathrm{Asn}^{92}$ have also been observed. Among the characteristic NOEs are the long-range connectivities between the His ${ }^{88} \mathrm{H}_{\delta}$ proton and the $\mathrm{H}_{\gamma}$ methyl protons of $\mathrm{Val}^{94}$ as well as that between the $\mathrm{HN}$ and $\mathrm{H}_{\gamma}$ of Phe ${ }^{89}$ with the side chain $\left(\mathrm{H}_{\gamma}\right)$ protons of $\mathrm{Thr}^{98}$. The NOE connectivities involving $\mathrm{Val}^{87}$ and $\mathrm{Thr}^{98}-\mathrm{Pro}^{99}$ residues confirm the cyclic nature of the peptide.

A.2. Cyclo(87-99) [Ala $\left.{ }^{91,96}\right] \mathrm{MBP}_{87-99}$ (II). $\mathrm{HN}-\mathrm{HN}$ and $\mathrm{H}_{\beta}-\mathrm{HN}(i, i+1)$ NOE connectivities are detected between all residues except prolines, while $\mathrm{H}_{\alpha}-\mathrm{HN}$ sequential connectivities are identified between residues $\mathrm{Val}^{87}-\mathrm{His}^{88}$, $\mathrm{Phe}^{89}-\mathrm{Phe}^{90}$, and $\mathrm{Ala}^{91}-\mathrm{Val}^{94}$ as well as between $\mathrm{Arg}^{97}$ and $\mathrm{Thr}^{98}$ residues (Figure 2D-F). HN-HN $(i, i+2)$ type connectivities are identified between $\mathrm{Ala}^{96}-\mathrm{Thr}^{98}$ residues and $\mathrm{H}_{\alpha}-\mathrm{HN}$ of $(i, i+2)$ type NOEs have been observed between residues $\mathrm{Val}^{87}-\mathrm{Phe}^{89}, \mathrm{Phe}^{89}$ $\mathrm{Ala}^{91}$, and $\mathrm{Val}^{94}-\mathrm{Ala}^{96}$. $\mathrm{A} \mathrm{H}_{\alpha}-\mathrm{HN}(i, i+3) \mathrm{NOE}$ between $\mathrm{His}^{88}$ $\mathrm{Ala}^{91}$ has also been identified. Among the noteworthy NOEs are the long-range connectivities between $\mathrm{Ala}^{91}$ and $\mathrm{Arg}^{97}$, which 

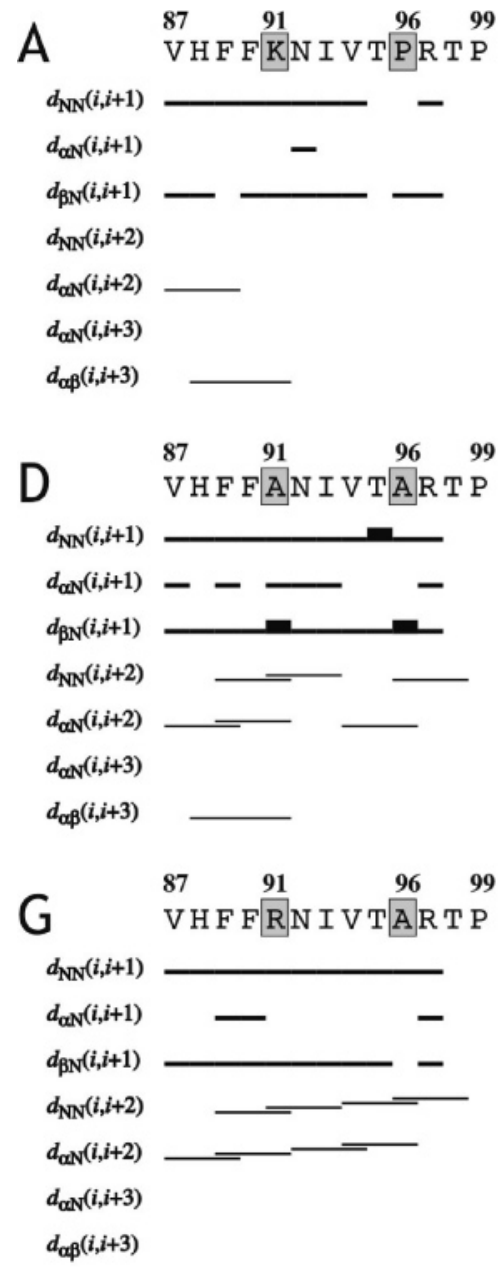
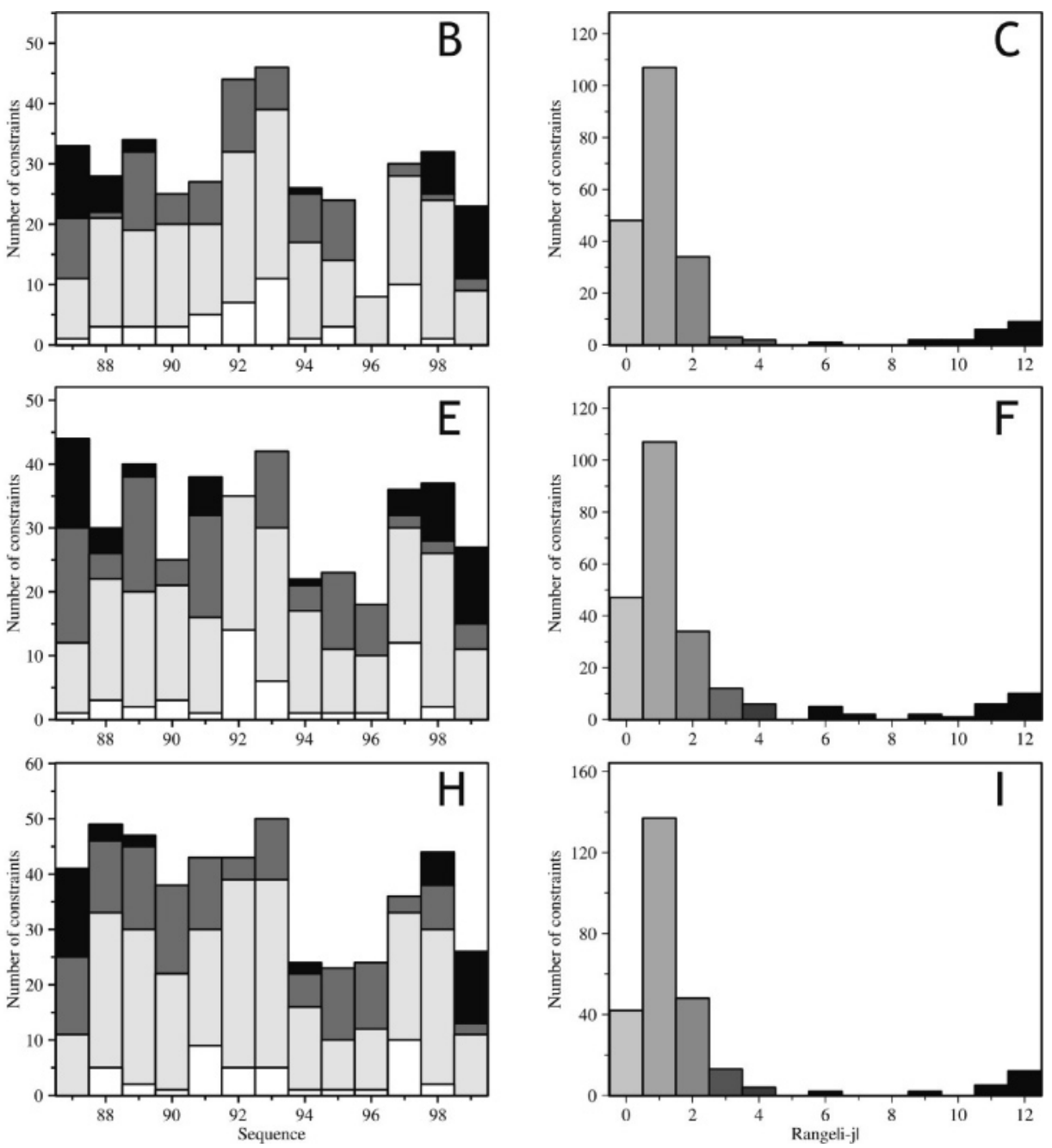

Figure 2. Schematic representation of the sequential and medium-range NOE connectivities of cyclo(87-99) $\mathrm{MBP}_{87-99}$, cyclo(87-99) [Ala ${ }^{91,96}$ ] $\mathrm{MBP}_{87-99}$, and cyclo(87-99) [ $\mathrm{Arg}^{91}, \mathrm{Ala}^{96}{ }^{9} \mathrm{MBP}_{87-99}$ in DMSO (A, D, and G, respectively). The number of NOE constraints per residue for each

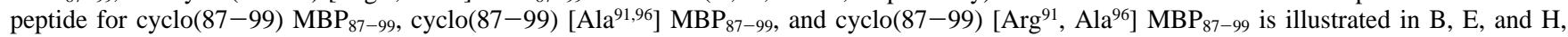
respectively. White, gray, dark gray and black vertical bars represent intraresidue, sequential, and medium-range and long-range connectivities,

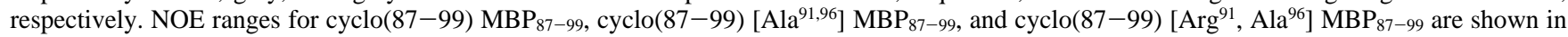
$\mathrm{C}, \mathrm{F}$, and I, respectively. All diagrams refer to meaningful NOE constraints extracted from $\tau_{\mathrm{m}}=300 \mathrm{~ms}$ NOESY.

are not detected in NOESY spectra of the other two peptides, cyclo(87-99) $\mathrm{MBP}_{87-99}$ and cyclo(87-99) [ $\mathrm{Arg}^{91}, \mathrm{Ala}^{96}$ ] $\mathrm{MBP}_{87-99}$. The NOE between the amide proton and the $\mathrm{H}_{\gamma}$ of Phe ${ }^{89}$ with the side chain $\left(\mathrm{H}_{\gamma}\right)$ protons of $\mathrm{Thr}^{98}$ are due to the cyclic conformation of the cyclo(87-99) $\left[\mathrm{Ala}^{91,96}\right] \mathrm{MBP}_{87-99}$ peptide.

A.3. Cyclo(87-99) [Arg $\left.{ }^{91}, \mathrm{Ala}^{96}\right] \mathbf{M B P}_{\text {87-99 }}$ (III). The NOE pattern involving $\mathrm{HN}-\mathrm{HN}, \mathrm{H}_{\alpha}-\mathrm{HN}$, and $\mathrm{H}_{\beta}-\mathrm{HN}(i, i+1)$ connectivities for this peptide is rather similar to these of the cyclo(87-99) [Ala $\left.{ }^{91,96}\right] \mathrm{MBP}_{87-99}$ analogue. HN-HN $(i, i+$ 2) type connectivities are observed for the fragments spanning the residues Phe ${ }^{89}-\mathrm{Ile}^{93}$ and $\mathrm{Val}^{94}-\mathrm{Thr}^{98}$, while $\mathrm{H}_{\alpha}-\mathrm{HN}(i, i+$ 2) type NOEs have been observed for regions $\mathrm{Val}^{87}-\mathrm{Arg}^{91}$ and $\mathrm{Asn}^{92}-\mathrm{Ala}^{96}$ (Figure 2G-I). Similar to cyclo(87-99) $\mathrm{MBP}_{87-99}$ and cyclo(87-99) [Ala $\left.{ }^{91,96}\right] \mathrm{MBP}_{87-99}$ peptides, the cyclic conformation of cyclo(87-99) [ $\mathrm{Arg}^{91}, \mathrm{Ala}^{96} \mathrm{MBP}_{87-99}$ analogue is also observed by the observed NOEs between $\mathrm{Val}^{87}$ and $\mathrm{Thr}^{98} / \mathrm{Pro}^{99}$ residues. Additionally, the long-range NOEs between the side chain $\left(\mathrm{H}_{\delta}, \mathrm{H}_{\epsilon}\right)$ protons of $\mathrm{His}^{88}$ residue and the side chain $\left(\mathrm{H}_{\gamma}\right)$ proton of $\mathrm{Val}^{94}$ are also observed in cyclo(87-99) [ $\left.\mathrm{Arg}^{91}, \mathrm{Ala}^{96}\right] \mathrm{MBP}_{87-99}$ peptide, in analogy to those observed in cyclo(87-99) $\mathrm{MBP}_{87-99}$ peptide. Consistently with the NOEs observed for the other two peptides, NOEs involving the $\mathrm{HN}$ and the $\mathrm{H}_{\gamma}$ of $\mathrm{Phe}^{89}$ residue and the side chain proton $\left(\mathrm{H}_{\gamma}\right)$ of $\mathrm{Thr}^{98}$ have been observed.

B. Chemical Shift Difference Analysis. Three diagrams illustrating the ${ }^{1} \mathrm{H}$ chemical shift differences between the peptides were plotted in order to illustrate the variation in chemical shifts, which are potential indicators for the conformational changes imposed by the replacement of the amino acids at positions 91 and 96 (Figure S1A-C, Supporting Information). These plots refer to the peptide pairs I and II (A), II-III (B), and I and III (C). The largest chemical shift variation in the first peptide pair I-III (A) was observed for $\operatorname{Thr}^{98}(>0.5 \mathrm{ppm})$, while smaller variations are calculated for $\mathrm{Val},{ }^{94} \mathrm{Thr}^{95}$, and $\mathrm{Arg}^{97}$, because of the replacement of $\mathrm{Pro}^{96}$ with $\mathrm{Ala}^{91}$. In the two other peptides pairs the largest chemical shift variation $(0.30$ $\mathrm{ppm}$ for $\mathrm{B}$ and $>0.30 \mathrm{ppm}$ for $\mathrm{C}$ ) is calculated for $\mathrm{Ile}^{93}$, which is located in the middle of the sequence and seems to be affected by modifications in both positions 91 and 96 .

Three other diagrams (Figure S1D-F, Supporting Information) illustrating the ${ }^{13} \mathrm{C}$ chemical shift differences $(\triangle \mathrm{CA}, \Delta \mathrm{CB})$ between the peptides were plotted as well, referring to the peptide pairs I and II (D), II and III (E), and I and III (F). The largest chemical shift difference variation in I-II (D) and I-III (E) plots is identified for the amino acids at positions 91 and 

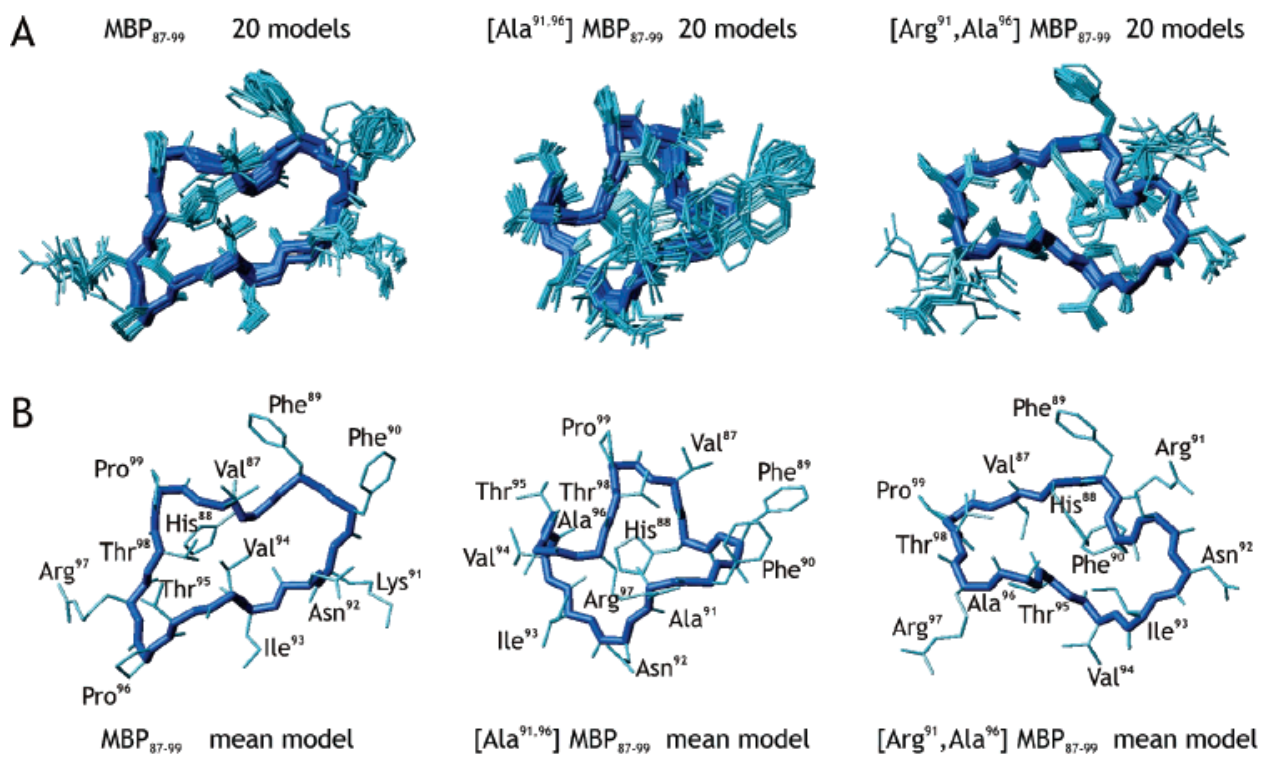

(A) Family of 20 energy-minimized DYANA models calculated for the cyclo(87-99) $\mathrm{MBP}_{87-99}$, cyclo(87-99) [Ala 91,96$] \mathrm{MBP}_{87-99}$, and cyclo(87-99) [Arg, ${ }^{91} \mathrm{Ala}^{96}{ }^{9} \mathrm{MBP}_{87-99}$ analogues and (B) the mean energy-minimized cyclo(87-99) $\mathrm{MBP}_{87-99}$, cyclo(87-99) [Ala ${ }^{91,96}$ ] $\mathrm{MBP}_{87-99}$, and cyclo(87-99) $\left[\mathrm{Arg}^{91}, \mathrm{Ala}^{96}\right] \mathrm{MBP}_{87-99}$ structures. The figure was generated with the MOLMOL program.

96. The chemical shift variation of the $\mathrm{C}_{\beta}$ atom of amino acid at position 91 is considerably smaller in the I-III (C) peptide pair because of the structural similarities of the amino acids Lys and Arg. The largest chemical shift variation in the peptide pair II-III (B) was observed for the amino acid at position 91 (Figure S1, Supporting Information).

C. Structure Calculations and Conformational Analysis. The average target function for the DYANA family of 20 calculated models (Figure 3A) was found to be $0.39 \pm 0.17 \AA^{2}$ for cyclo(87-99) $\mathrm{MBP}_{87-99}, 0.09 \pm 0.04 \AA^{2}$ for cyclo(87-99) [Ala ${ }^{91,96}$ ] $\mathrm{MBP}_{87-99}$, and $0.20 \pm 0.11 \AA^{2}$ for cyclo(87-99) $\left[\mathrm{Arg}^{91}, \mathrm{Ala}^{96} \mathrm{MBP}_{87-99}\right.$ models. No consistent violations existed at the final DYANA run and no constraint violation was found larger than $0.30 \AA$. The final (I) REM models exhibit pairwise rmsd values for all residues $0.33 \pm 0.14 \AA$ (BB), $1.33 \pm 0.42$ $\AA$ (HA) for the 20 structures and $0.23 \pm 0.09 \AA$ (BB), $0.91 \pm$ $0.31 \AA$ (HA) for the mean structure (Figure $3 \mathrm{~B}$ ), respectively. The rmsd values for the (II) REM ensemble are $0.31 \pm 0.11 \AA$ (BB), $0.90 \pm 0.26 \AA$ (HA) for the 20 models and $0.21 \pm 0.07$ $\AA$ (BB), $0.62 \pm 0.18 \AA$ (HA) for the mean structure while for (III) they are found to be $0.35 \pm 0.21 \AA$ (BB), $0.80 \pm 0.23 \AA$ (HA) for the 20 models and $0.27 \pm 0.08 \AA$ (BB), $0.59 \pm 0.11$ $\AA$ (HA) for the mean structure, respectively. Statistical data for REM models and average structure are given in the Supporting Information.

D. 3D Solution Structures. The NMR data for the three analogues indicate that $\mathrm{Val}^{87}$ remains in close spatial proximity with $\mathrm{Pro}^{99}$. Long-range NOEs between residues $\mathrm{Val}^{87}$ and $\mathrm{Thr},{ }^{98}$ $\mathrm{Val}^{87}$ and $\mathrm{Pro}^{99}$, $\mathrm{His}^{88}$ and $\mathrm{Thr}^{98}$, $\mathrm{His}^{88}$ and $\mathrm{Pro}^{99}$, as well as $\mathrm{Il}^{93}$ with $\mathrm{Thr}^{98}$ are fully consistent with a cyclic peptide where $\mathrm{Val}^{87}$ and Pro $^{99}$ are expected to be linked through a peptide bond. In general, the cyclo(87-99) $\mathrm{MBP}_{87-99}$ and cyclo(87-99) [Ala ${ }^{91,96}$ ] $\mathrm{MBP}_{87-99}$ peptides exhibit a lower number of NOE cross-peaks (622 and 572 cross-peaks, respectively) relative to the cyclo(87-99) [ $\left.\mathrm{Arg}^{91}, \mathrm{Ala}^{96}\right] \mathrm{MBP}_{87-99}$ peptide (685 NOE crosspeaks).

The cyclic conformation of cyclo(87-99) [ $\mathrm{Arg}^{91}, \mathrm{Ala}^{96}$ ] $\mathrm{MBP}_{87-99}$ analogue favors the formation of a hydrogen bond between $\mathrm{Val}^{87} \mathrm{H}-\mathrm{O} \gamma 1 \mathrm{Thr}^{98}$, observed in the family of 20 best DYANA structures, while a turn structure is adopted by $\mathrm{Phe}^{90}$ $\mathrm{Arg}^{91}-\mathrm{Asn}^{92}-\mathrm{Ile}^{93}$ and $\mathrm{Val}^{94}$ residues. Furthermore, the $\mathrm{H}_{\alpha}(i)-$
$\mathrm{HN}(i+2)$ type NOE connectivities for the regions covered by $\mathrm{Val}^{87}$-Arg ${ }^{91}$ and $\mathrm{Asn}^{92}-\mathrm{Ala}^{96}$, suggest a type II $\beta$-turn for this segment. Additionally, the observed NOE cross-peaks involving the $\mathrm{Thr}^{95}-\mathrm{Ala}^{96}-\mathrm{Arg}^{97}$ and $\mathrm{Thr}^{98}$ residues suggest the formation of a second turn (probably a U-type turn) (Figure 3).

According to the NMR analysis and structure calculations presented here, cyclo(87-99) [Ala $\left.{ }^{91,96}\right] \mathrm{MBP}_{87-99}$ differs from both cyclo(87-99) $\mathrm{MBP}_{87-99}$ and cyclo(87-99) [Arg ${ }^{91}, \mathrm{Ala}^{96}$ ] $\mathrm{MBP}_{87-99}$, while the latter two APLs share some similar conformational features. Indeed, only in the cyclo(87-99) $\left[\mathrm{Ala}^{91,96}\right] \mathrm{MBP}_{87-99}$ analogue are the residues 91 and 97 found to be in close proximity as manifested by long-range NOEs, such as the amide proton of $\mathrm{Ala}^{91}$, the $\mathrm{H}_{\alpha}$ and $\mathrm{H}_{\delta}$ protons of $\operatorname{Arg}^{97}$, the $\mathrm{H}_{\beta}$ proton of $\mathrm{Ala}^{91}$ and $\mathrm{H}_{\alpha}$, and the $\mathrm{H}_{\delta}$ protons of $\mathrm{Arg}^{97}$. The vicinity of neutral $\mathrm{Ala}^{91}$ with positively charged $\mathrm{Arg}^{97}$ is favorable in cyclo(87-99) [Ala $\left.{ }^{91,96}\right] \mathrm{MBP}_{87-99}$, while the vicinity of positively charged $\mathrm{Lys}^{91} / \mathrm{Arg}^{91}$ and $\mathrm{Arg}^{97}$ does not seem favorable in cyclo(87-99) $\mathrm{MBP}_{87-99}$ and cyclo(8799) $\left[\mathrm{Arg}^{91}, \mathrm{Ala}^{96}\right] \mathrm{MBP}_{87-99}$ peptide, respectively. In contrast, their side chains are oriented toward opposite directions possibly due to charge repulsion. Moreover, NOEs between (i) $\mathrm{H}_{\beta}$ protons of $\mathrm{Ala}^{91}$ with $\mathrm{H}_{\beta}$ protons of $\mathrm{Thr}^{95}$ and (ii) $\mathrm{H}_{\beta}$ protons of $\mathrm{Ala}^{91}$ with the amide and $\mathrm{H}_{\beta}$ proton of $\mathrm{Thr}^{98}$ in the cyclo(87-99) [Ala ${ }^{91,96}$ ] $\mathrm{MBP}_{87-99}$ analogue indicate the formation of a backbone turn in the $\mathrm{Ala}^{91}-\mathrm{Asn}^{92}-\mathrm{Ile}^{93}-\mathrm{Val}^{94}-\mathrm{Thr}^{95}-\mathrm{Ala}^{96}-\mathrm{Arg}^{97}$ segment. Only in the case of the $\operatorname{cyclo}(87-99)$ [Ala ${ }^{91,96}$ ] $\mathrm{MBP}_{87-99}$ do analogue residues His ${ }^{88}$, $\mathrm{Phe}^{89}$, and $\mathrm{Phe}^{90}$ form a turn-like structure partially resembling a $3_{10}$ helix conformation, which is supported by NOEs between $\mathrm{Val}^{87}$ with $\mathrm{Phe}^{90}$ as well as His $^{88}$ with Ala. ${ }^{91}$

In the cyclo(87-99) $\mathrm{MBP}_{87-99}$ analogue, residues in the sequence 88-93 form again a turn-like structure, which is supported by strong NOEs of $\mathrm{H}_{\alpha}(i)-\mathrm{HN}(i+1)$ type and NOEs between the side chain protons $\left(\mathrm{H}_{\delta}\right)$ of $\mathrm{His}^{88}$ and the side chain protons $\left(\mathrm{H}_{\gamma}\right)$ of $\mathrm{Val}^{94}$. Additionally, the existence of $\mathrm{H}^{\beta}(\mathrm{i})-$ $\mathrm{HN}(i+2)$ cross-peaks between residues $\mathrm{Val}^{87}-\mathrm{Phe}^{89}$ and $\mathrm{Phe}^{90}$ $\mathrm{Thr}^{95}$ indicates the formation of a type II $\beta$-turn for this segment. A second turn is expected for the segment $\mathrm{Val}^{94}-\mathrm{Thr}^{95}-\mathrm{Pro}^{96}$ $\mathrm{Arg}^{97}-\mathrm{Thr}^{98}-\mathrm{Pro}^{99}$, which is further supported by the existence of $\mathrm{Thr}^{95} \mathrm{H}_{\gamma}-\mathrm{Thr}^{98} \mathrm{HN}$ and $\mathrm{Thr}^{95} \mathrm{H}_{\gamma}-\mathrm{Pro}^{99} \mathrm{H}_{\delta}$ cross-peaks. The calculated DYANA models further support this local 
A.
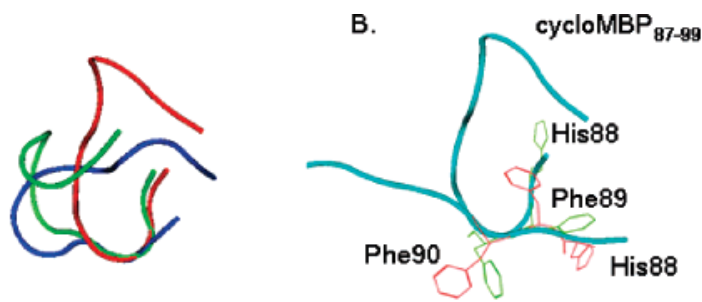

c.
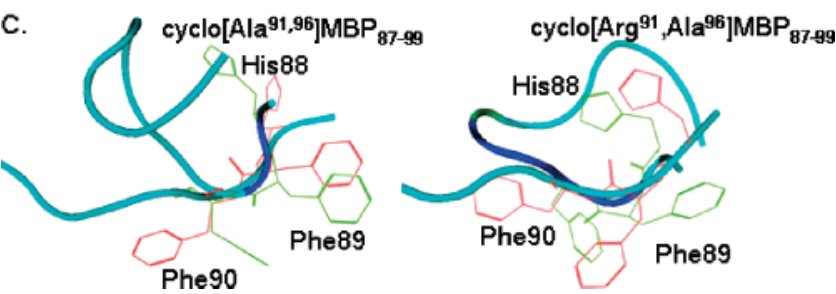

Figure 4. (A) Superimposition of the sequence 88-92 of the cyclic APLs cyclo(87-99) MBP $87-99$ (red), cyclo(87-99) [Ala $\left.{ }^{91,96}\right] \mathrm{MBP}_{87-99}$ (green), and cyclo(87-99) [ $\mathrm{Arg}^{91}, \mathrm{Ala}^{96}{ }^{9} \mathrm{MBP}_{87-99}$ (blue). $\mathrm{C}_{\alpha}$ rmsd is $2.09 \AA$. (B) Superimposition of the sequence $88-92$ of the native peptide $\mathrm{MBP}_{85-98}$ obtained from X-ray crystallography (red) and cyclic (87-99) $\mathrm{MBP}_{87-99}$ (green). $\mathrm{C}_{\alpha}$ rmsd is $2.26 \AA$. (C) Superimposition of the sequence 88-92 of the cyclic APLs with their linear counterparts: cyclo(87-99) [Ala $\left.{ }^{91,96}\right] \mathrm{MBP}_{87-99}$ and $\left[\mathrm{Ala}^{91,96}\right] \mathrm{MBP}_{87-99}$ (left), cyclo(87-99) [ $\left.\mathrm{Arg}^{91}, \mathrm{Ala}^{96}\right] \mathrm{MBP}_{87-99}$ and $\left[\mathrm{Arg}^{91}, \mathrm{Ala}^{96}\right] \mathrm{MBP}_{87-99}$ (right). $\mathrm{C}_{\alpha}$ rmsd values are $2.19 \AA$ and $1.46 \AA$, respectively. The linear APLs are colored red, and the cyclic ones are colored green.

conformation, where two $(i, i+2)$ hydrogen bonds between the $\mathrm{Thr}^{95}$ amide proton and the oxygen atom of $\mathrm{Ile}^{93}$ and between the $\mathrm{Arg}^{97}$ amide proton and the $\mathrm{O} \gamma 1$ of $\mathrm{Thr}^{95}$ have been observed in all 20 calculated models. The overall backbone conformation, though, is not as compact as in the two cyclic antagonist APLs, as there is no turn formed in the middle sequence $92-96$.

Despite the structural similarity between the three peptides and their cyclic nature, a superimposition of the backbone segment for the three cyclic conformers reveals significant differences in backbone conformation (Figures 3A and 4). To quantify the relative change of the position of the imidazole $\mathrm{His}^{88}$ with respect to the phenyl rings $\mathrm{Phe}^{89}$ (primary TCR contacts) and Phe ${ }^{90}$ (primary MHC contact), we measured the sides of the triangles formed by the centroids of the rings (Figure 5). In cyclo(87-99) $\mathrm{MBP}_{87-99}$ the phenyl ring of $\mathrm{Phe}^{89}$ lies almost evenly between the rings of $\mathrm{His}^{88}$ and $\mathrm{Phe}^{90}$, the centroids of rings 88 and 89 being separated by a distance of $12.52 \AA$. This distance is shorter in both cyclo(87-99) $\left[\mathrm{Ala}^{91,96}\right] \mathrm{MBP}_{87-99}$ and cyclo(87-99) $\left[\mathrm{Arg}^{91}, \mathrm{Ala}^{96}\right] \mathrm{MBP}_{87-99}, 10.62 \AA$ and 7.13 $\AA$ respectively, and combined with the fact that $\mathrm{Phe}^{89}$ and the amino acid in position 91 (Arg or Ala) are found in spatial proximity in both of the antagonist APLs, creating a bend in the middle segment of the sequence, this leads to more compact backbone conformations in solution.

E. Cyclization and Biological Implications. Cyclization of the linear $\mathrm{MBP}_{87-99}$ epitope, which was shown to be an agonist inducing EAE, caused this activity to be retarded, without a simultaneous reversal of the disease. Cyclic $\mathrm{MBP}_{87-99}$, thus, is neither an agonist nor an antagonist. On the other hand, cyclo(87-99) [Ala ${ }^{91,96}$ ] $\mathrm{MBP}_{87-99}$ and cyclo(87-99) [ $\mathrm{Arg}^{91}, \mathrm{Ala}^{96}$ ] $\mathrm{MBP}_{87-99}$ presented similar biological activity as their linear counterparts: they inhibited EAE induced by encephalitogenic $\mathrm{MBP}_{74-85}$ in Lewis rats. The structural effect of cyclization to the linear analogues was sought in order to explain the observed biologic activity. The ability of a peptide-MHC complex to activate a T-cell generally correlates with the strength and duration of TCR binding. ${ }^{9}$ The high affinity of TCR for the pMHC and long half-lives of binding have been associated with agonist action, whereas low affinity of TCR for the pMHC with weak interactions formed and decreased half-lives of binding characterize TCR antagonism.

MS is associated with MHC II molecules (in humans referred to as Human Leukocyte Antigens, HLA). Hahn et al. ${ }^{10}$ have reported the crystal structure (PDB code 1ymm) of the trimolecular complex of $\mathrm{MBP}_{85-98}$, HLA-DRB1*1501, and a TCR isolated from a patient with relapsing-remitting MS. ${ }^{11,12}$ This TCR represents one of the best-characterized TCRs from a human autoimmune disease, and it presents a topology notably different from that of antimicrobial ones. ${ }^{13-15}$ The TCR contacts only the $\mathrm{N}$-terminal region of the peptide and specifically residues at positions $\mathrm{P} 2 \mathrm{His}^{88}$ and $\mathrm{P} 3 \mathrm{Phe}^{89}$. The natural ligand was isolated from the complex, and its conformation was used as a basis for comparison with cyclic MBP analogues.

When superimposing the sequence $88-92$, the $\mathrm{C}_{\alpha}$ rmsd is $2.26 \AA$. Phe ${ }^{90}$ binds in a large hydrophobic groove of HLA$\mathrm{DR} 2 \mathrm{~b}$ in the X-ray structure. According to structure comparison of the NMR structure (Figure 4B), the phenyl ring is orientated toward the same space with the corresponding residue side chain of the linear peptide. Both TCR contacts, though, lie in a different region in space.

In order to compare the structure of the linear peptide as reported in the crystal model with the structure of the cyclic MBP derivatives, docking simulations were carried out on the cyclo(87-99) $\mathrm{MBP}_{87-99}$ peptide (the cyclic peptide with the native sequence) with MHC. Hahn et al. have demonstrated that (i) TCR CDR3 loops create a dome-shaped cavity, large enough to accommodate both an MHC residue DR $\beta 81$ His (CDR3a loop) and a peptide side chain $\mathrm{His}^{88}$ (both CDR3a and CDR3 $\beta$ loop) and (ii) $\mathrm{Ph}^{89}$ lies between the $\mathrm{CDR} 3 \beta$ loop and a hydrophobic region of the DR molecule. Our data for the cyclic counterpart reveal that the amino residue Pro ${ }^{97}$ is posed in such a way that it occupies the same region in space as $\mathrm{His}^{88}$ of the linear peptide, thus fulfilling the demands of the receptor for a bulky and hydrophobic substrate group at this cavity (Figure 6). Moreover, the $\mathrm{Phe}^{89}$ aromatic ring in the cyclo(87-99) $\mathrm{MBP}_{87-99}$ orients toward the cavity formed by the $\mathrm{Phe}^{22}, \mathrm{Phe}^{24}$, and $\mathrm{Phe}^{54}$ residues of the MHC in a remarkably similar way with the side chain of the same phenylalanine residue of the linear peptide which is accommodated in this hydrophobic cavity, according to the X-ray structure.

Smith et al. report that a large hydrophobic $\mathrm{P} 4$ pocket, which is occupied by $\mathrm{Phe}^{90}$ of the linear $\mathrm{MBP}_{85-98}$ peptide, makes an important contribution to the binding of the MBP peptide to HLA-DR2. This hydrophobic pocket is comprised of DRb79 Ala, b26 Phe, and b78 Tyr residues (Figure 6). Docking simulations display that the $\mathrm{P} 4$ pocket is occupied by $\mathrm{His}^{88}$ of the cyclo(87-99) $\mathrm{MBP}_{87-99}$ model and the binding of an aromatic substrate amino acid for this cage is conserved. So $\mathrm{His}^{88}$, which has been inserted into this cage and replaces $\mathrm{Phe}^{90}$ in space, exhibits stabilization through hydrophobic and Van der Waals interactions. Furthermore, it is observed that $\mathrm{Phe}^{90}$ of the cyclo(87-99) $\mathrm{MBP}_{87-99}$ peptide is solvent exposed (Figure 6). The cyclic APL has a very bulky conformation, and the overall topology is such that the TCR probably cannot approach, either with the diagonal mode suggested by the X-ray structure or with a centered approach over the peptide-HLA complex. Overall, it is clearly indicated that the conformational features of the MBP cyclic peptides as determined by NMR studies in DMSO solution are of great importance. These structurally constrained cyclic MBP analogues, according to docking simulation studies, could retain their characteristics for efficient binding to MHC receptor. On the other hand, 


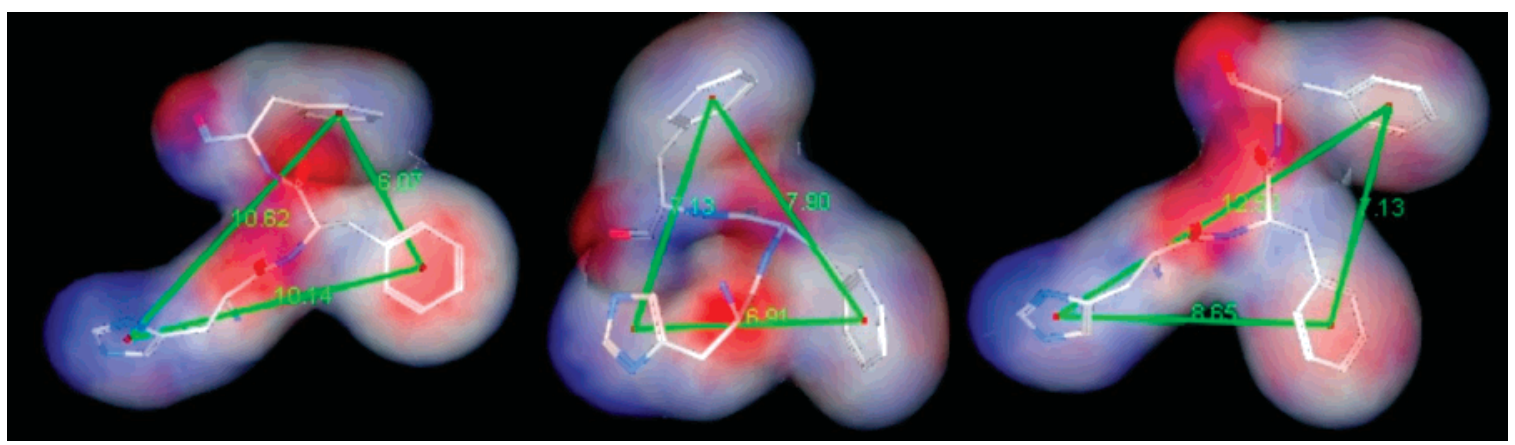

Figure 5. Triangles formed by ring centroids of $\mathrm{His}^{88}$, $\mathrm{Phe}^{89}$, and $\mathrm{Phe}^{90}$ for the cyclic APLs $\left[\mathrm{Arg}^{91}, \mathrm{Ala}^{96}\right] \mathrm{MBP}_{87-99}(\mathrm{left})$, $\left[\mathrm{Ala}^{91,96}\right] \mathrm{MBP}_{87-99}$ (middle), and $\mathrm{MBP}_{87-99}$ (right). Lengths of the sides between the centroids are shown with green lines.

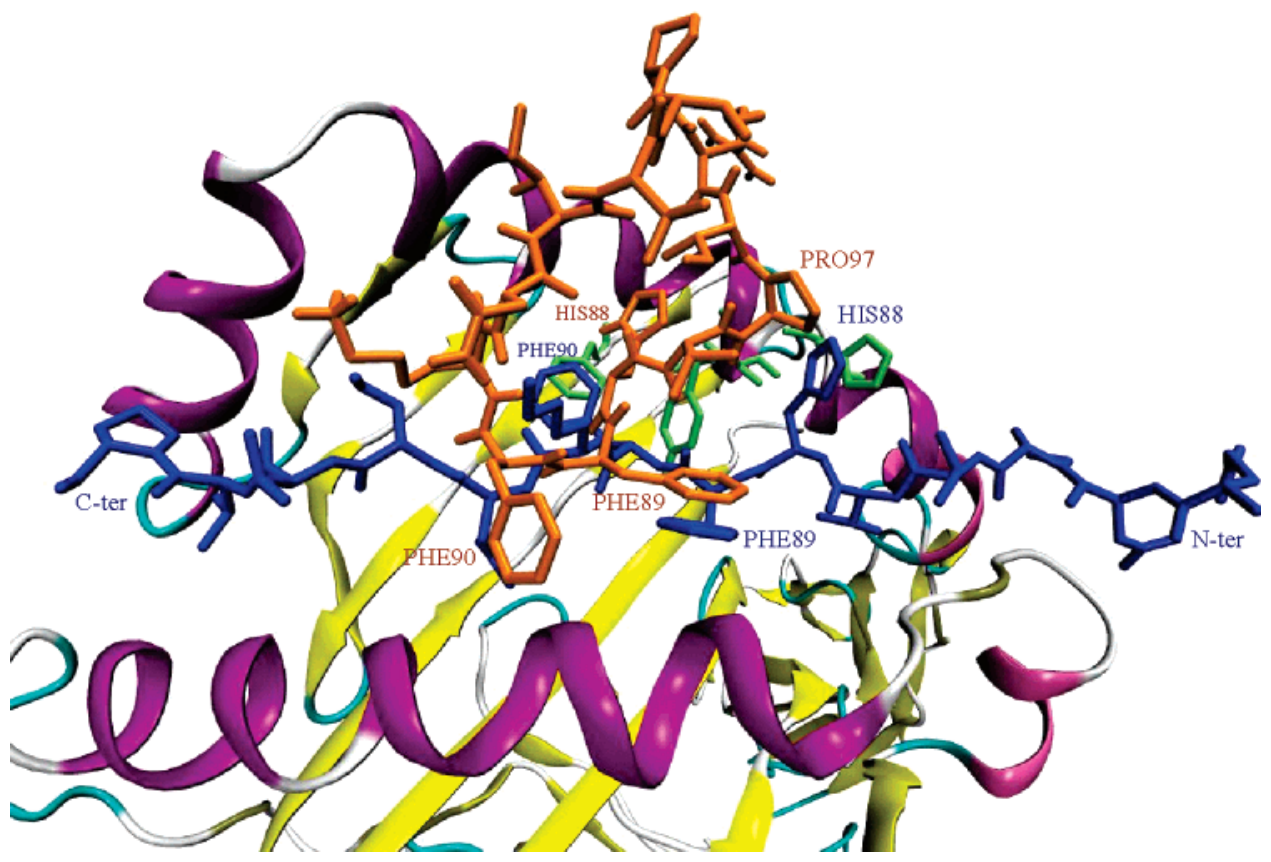

Figure 6. Representation of the cyclo(87-99) $\mathrm{MBP}_{87-99}-\mathrm{MHC}$ model complex. MHC is shown as a cartoon representation, and the cyclo(87-99) $\mathrm{MBP}_{87-99}$ docked peptide is shown as orange. For comparison, the linear peptide $\mathrm{MBP}_{85-98}$ is shown at its crystallographic position as blue. The $\mathrm{DRb}$ aminoacids of $\mathrm{MHC}$ are shown as lime. $\mathrm{His}^{88}, \mathrm{Phe}^{89}$, and $\mathrm{Phe}^{90}$ of both cyclo and linear peptide are labeled.

being rather bulky compared to their parent linear peptides, they could adjust the interaction interface between MHC and TCR receptors.

E. D. Mantzourani et al. proposed putative bioactive conformations for the linear peptides $\left[\mathrm{Ala}^{91,96}\right] \mathrm{MBP}_{87-99}{ }^{16}$ and $\left[\mathrm{Arg}^{91}\right.$, $\mathrm{Ala}^{96}$ ] $\mathrm{MBP}_{87-99}{ }^{17}$, derived after comparison with the X-ray structure. These linear conformations were superimposed with their cyclic counterparts, as shown in Figure $4 \mathrm{C}$. The $\mathrm{C}_{\alpha} \mathrm{rmsd}$ for the sequence $88-92$ is $2.18 \AA$ for cyclo [ $\mathrm{Ala}^{91,96}$ ] $\mathrm{MBP}_{87-99}$ and $1.46 \AA$ for cyclo $\left[\mathrm{Arg}^{91}, \mathrm{Ala}^{96}\right] \mathrm{MBP}_{87-99}$. In both cyclic APLs, $\mathrm{C}_{\beta}$ of Phe ${ }^{90}$ remains in exactly the same position, but the ring presents an altered orientation. The side chains of $\mathrm{Ph}^{89}$ in cyclo $\left[\mathrm{Arg}^{91}, \mathrm{Ala}^{96}\right] \mathrm{MBP}_{87-99}$ are characterized by the same feature, whereas in cyclo [ $\left.\mathrm{Ala}^{91,96}\right] \mathrm{MBP}_{87-99}$ the rings lie within the same region in space. The amino acid $\mathrm{His}^{88}$ is shifted upward in both cyclic APLs, as a result of the cyclic backbone. The overall topology of both cyclic antagonist APLs is such that again the TCR cannot approach with the diagonal mode suggested by the X-ray structure. According to the rigid docking simulation, the cyclic bulky peptide is accommodated by MHC. A more conventional mode of binding of the TCR to the APLHLA complex, i.e., centered over the peptide-HLA surface, would result in extensive contacts with both the MHC and $\mathrm{MBP}_{87-99}$ analogues. Whether these contacts would result in an optimal fit, inducing in turn immune response with sufficient modification of the inflammatory cytokine environment providing protection against EAE, is strongly dependent on the conformational freedom and on restriction of the cyclic peptides. Such properties could be fine-tuned through structure-based engineering of $\mathrm{MBP}_{87-99}$ sequence according to the acquired NMR structural information.

F. Proposal of a Pharmacophore Model. The NMR analysis identified structural data could lead to the establishment of a pharmacophore model for APLs presenting EAE antagonism. MOE 2006.08 25 was used for the generation of the pharmacophore model.

An essential characteristic for EAE antagonism is the formation of weak interactions between the bimolecular complex APL-MHC with the T-cell receptor. Structural data from the analysis of cyclo(87-99) $\mathrm{MBP}_{87-99}$ suggest that the lack of bioactivity might be due to the overall bulky orientation of the APL over the MHC molecule, which prevents any subsequent binding of the TCR. Therefore, the first feature in the proposed pharmacophore model is the exclusion volume V1 (Figure 7) dictated by the space occupied by cyclo(87-99) $\mathrm{MBP}_{87-99}$ after superimposition onto the other two cyclic antagonist APLs (Figure 5). The radius of the sphere is $2.8 \AA$. The second feature $\mathrm{F} 1$ is located in the region of the phenyl ring of $\mathrm{Phe}^{90}$. The 


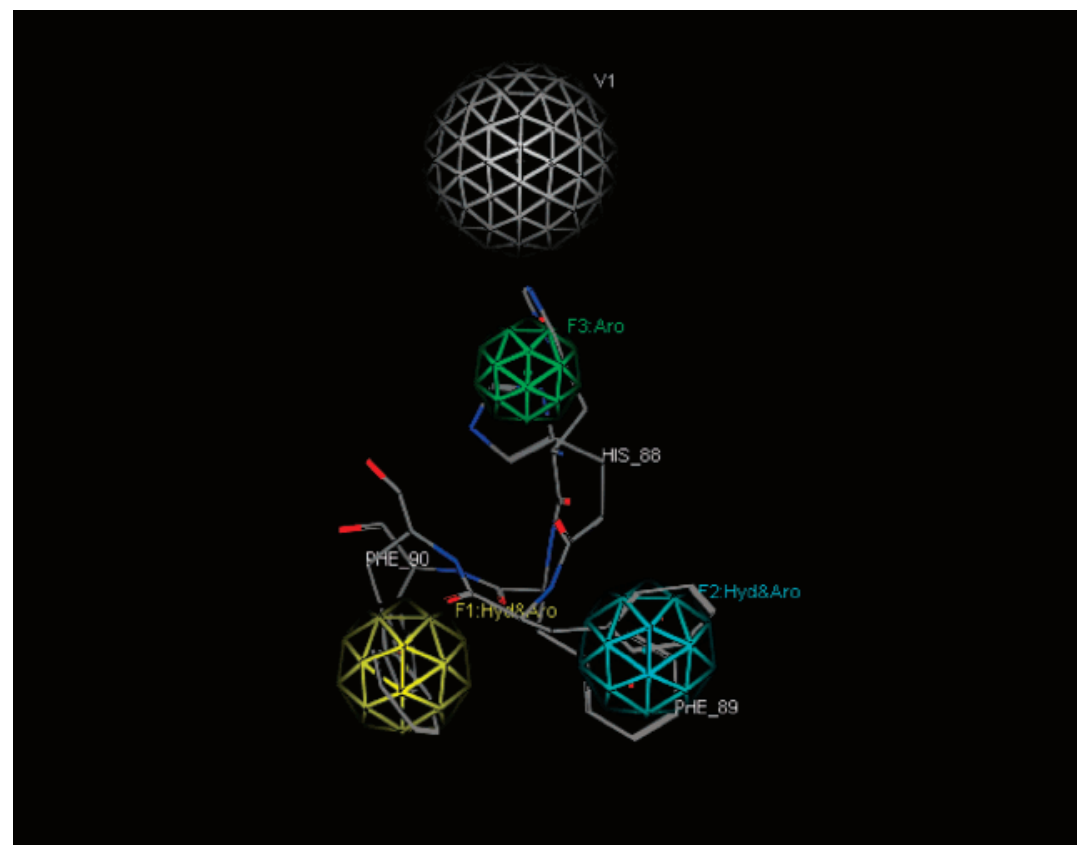

Figure 7. Pharmacophore model generated by the structural data obtained from the conformational analysis for the cyclic APLs. Exclusion volume V1 is presented with a gray sphere, feature F1 $\left(\mathrm{Phe}^{90}\right)$ with a yellow sphere, F2 (Phe $\left.{ }^{89}\right)$ with cyan, and F3 (Phe $\left.{ }^{88}\right)$ with a green sphere.

center of the sphere in this case lies on the virtual line connecting the centroids of the ring in the conformations of the two antagonistic APLs, while the radius is $1.9 \AA$, creating a volume big enough to accommodate a hydrophobic and aromatic ring. The same procedure has been followed for the third feature F2, for which the center is placed on the virtual line connecting the centroids of the phenyl ring of $\mathrm{Phe}^{89}$ in cyclo(87-99) [Arg ${ }^{91}$, $\mathrm{Ala}^{96} \mathrm{MBP}_{87-99}$ and cyclo(87-99) [Ala ${ }^{91,96} \mathrm{MBP}_{87-99}$. The sphere should again be occupied by a hydrophobic and aromatic ring, selecting a radius of $1.9 \AA$ for the reason mentioned above. The last feature in the pharmacophore model, F3, was once more chosen to be generated where the imidazole ring of $\mathrm{His}^{88}$ lies in the two APLs. The radius of the sphere is once again $1.9 \AA$, and the desired characteristic is occupation by an aromatic group.

The pharmacophore model defined in this study contains information regarding $\mathrm{MHC}\left(\mathrm{Phe}^{90}\right)$ and TCR anchors (His ${ }^{88}$, $\mathrm{Phe}^{89}$ ) as well as the overall volume of the target molecules that should not occlude weak interactions with an approaching TCR and therefore may suppress EAE antagonism.

\section{Concluding Remarks}

We have determined the conformational properties of MBP peptide epitopes modified through engineering their sequence and evaluated local structural variation due to these modifications. In this way, we aim to correlate observed antagonistic activity with the structure of these restricted cyclic analogues using NMR techniques. High-resolution 3D models of synthetic MBP peptides reveal the conformational differences and similarities between linear and cyclic APLS. In combination with the known effect on their bioactivity, this could lead to the exploration of the molecular basis of EAE antagonism and the rational design of non-peptide mimetics.

NMR shows that among the three peptides the proximity of residues in positions 91 and 97 is favorable only in cyclo(8799) $\left[\mathrm{Ala}^{91,96}\right] \mathrm{MBP}_{87-99}$. When Ala is replaced by $\mathrm{Lys}^{91} / \mathrm{Arg}^{91}$ in cyclo(87-99) $\mathrm{MBP}_{87-99}$ and in cyclo(87-99) [ $\mathrm{Arg}^{91}, \mathrm{Ala}^{96}$ ] $\mathrm{MBP}_{87-99}$, respectively, no NOE between the long, positively charged $\mathrm{Lys}^{91} / \mathrm{Arg}^{91}$ side chain and that of $\mathrm{Arg}^{97}$ is observed.
In these cases, charge repulsion between $\mathrm{Lys}^{91} / \mathrm{Arg}^{91}$ and $\mathrm{Arg}^{97}$ seems to account for the orientation of Lys/Arg and $\mathrm{Arg}^{97}$ side chains toward opposite directions. In cyclo(87-99) [ $\mathrm{Arg}^{91}$, $\left.\mathrm{Ala}^{96}\right] \mathrm{MBP}_{87-99}$, there is a $\beta$ II turn formed in the sequence 92-96, a feature which is not present in cyclo(87-99) $\mathrm{MBP}_{87-99}$. This conformational characteristic is responsible for the more compact conformations of the antagonist APLs, which in turn possibly allows the TCR to approach, form weak interactions with the pMHC, and induce biochemical activity which is inhibitory over the agonist-delivered signals.

The design and synthesis of cyclic peptide analogues is the most important step in the rational design of peptidomimetics or non-peptide mimetics. The conformational flexibility of a cyclic analogue is restricted, and the orientation of side chain groups important for binding could lead to the design of nonpeptide analogues. In this paper, based on the conformations of the studied cyclic analogues obtained from the NMR analysis, we proposed a pharmacophore model, which will be the first step towards the design and synthesis of organic molecules using rigid templates.

\section{Experimental Methods}

A. Peptide Synthesis and Purification. Protected (87-99) $\mathrm{MBP}_{87-99}$, cyclo(87-99) [Arg91, $\mathrm{Ala}^{96}$ ] $\mathrm{MBP}_{87-99}$, and cyclo(8799) $\left[\mathrm{Ala}^{91,96}\right] \mathrm{MBP}_{87-99}$ peptide analogues were synthesized in the solid phase by Fmoc/tBu methodology using 2-chlorotrityl chloride (CLTR-Cl) resin and $\mathrm{N}^{\mathrm{a}}$-Fmoc (9-fluorenylmethyloxycarboxyl)protected amino acids as previously described. ${ }^{7,8}$ A cyclic conformation is imposed through the condensation reaction, resulting in the formation of an amide bond through the $\mathrm{N}$-terminal $\mathrm{Val}^{87}$ and C-terminal Pro ${ }^{99}$ amino acids. The cyclization was achieved using $O$-benzotriazol-1-yl- $N, N, N^{\prime}, N^{\prime}$-tetramethyluronium tetrafluoroborate (TBTU), 1-hydroxy-7-azabenzotriazole (HOAt), and 2,4,6-collidine, allowing fast reaction and high-yield final cyclic products (yield 95-98\%). The purification and identification of final cyclic peptides were assessed using semipreparative reversed phase high-performance liquid chromatography (RP-HPLC) and electron spray ionization (ESI) mass spectroscopy (MS), respectively. Scheme 1 shows the primary structure of the cyclic analogues. After purification, the synthesized peptides showed a purity of $95 \%$. The lack of any charged group of cyclo(87-99) $\left[\mathrm{Ala}^{91,96}\right] \mathrm{MBP}_{87-99}$ in position 
Scheme 1. Primary Structure of the Cyclic Analogues under Study

cyclo(87-99) $\mathrm{MBP}_{87-99}$

Yal-His-Phe-Phe-Lys-Asn-Ile-Val-Thr-Pro-Arg-Thr-Pro

cyclo(87-99) $\left[\right.$ Ala $^{91.96}$ MBP $_{87-99}$

Yal-His-Phe-Phe-Ala-Asn-lle-Val-Thr-Ala-Arg-Thr-Pro

cyclo(87-99) $\left[\mathrm{Arg}^{91}\right.$, Ala $\left.^{96}\right] \mathrm{MBP}_{87-99}$ Yal-His-Phe-Phe-Arg-Asn-lle-Val-Thr-Ala-Arg-Thr-Pro

91 leads to a reduced solubility in water compared to the other two cyclic APLs, namely $1.15 \mathrm{mg} / 100 \mu \mathrm{L}$, whereas values for cyclo(87-99) $\mathrm{MBP}_{87-99}$ and cyclo(87-99) [Arg91, Ala96] $\mathrm{MBP}_{87-99}$ are $16 \mathrm{mg} / 100 \mu \mathrm{L}$ and $16.25 \mathrm{mg} / 100 \mu \mathrm{L}$, respectively.

Dimethylsulfoxide DMSO- $d_{6}$ (euroiso-top, C.E. Saclay, France) was used as the deuterated solvent in NMR experiments, ${ }^{26}$ and the peptides were dissolved to a final concentration of $2-2.5 \mathrm{mM}$ in order to record 1D and 2D NMR spectra. The NMR studies have been performed in DMSO in conjunction with previous studies of other MBP peptide analogues, mimicking a prototypical amphiphilic environment.

B. NMR Spectroscopy. Data were acquired at $298 \mathrm{~K}$ on a Bruker Avance 600 and $700 \mathrm{MHz}$ spectrometers. ${ }^{1} \mathrm{H}$ 1D NMR spectra were recorded using a spectral width of $12-17 \mathrm{ppm}$ with or without presaturation of the $\mathrm{H}_{2} \mathrm{O}$ signal. ${ }^{1} \mathrm{H}-{ }^{1} \mathrm{H}$ 2D TOCSY ${ }^{27,28}$ (Figure 1) spectra were recorded using the MLEV-17 spin lock sequence and $\tau_{\mathrm{m}}=80 \mathrm{~ms}$, and ${ }^{1} \mathrm{H}_{-}{ }^{13} \mathrm{C}$ HSQC ${ }^{29}$ with $200.791 \mathrm{ppm}$ spectral width in $\mathrm{F} 1 .{ }^{1} \mathrm{H}-{ }^{1} \mathrm{H}$ TPPI NOESY ${ }^{30,31}$ spectra were acquired using mixing time $\tau_{\mathrm{m}}=300 \mathrm{~ms}$, applying water suppression during the relaxation delay and mixing time. All 2D spectra were acquired with 10.014 ppm spectral width, consisting of $2 \mathrm{~K}$ data points in the $\mathrm{F} 2$ dimension, 16-32 transients, and 512-1024 complex increments in the F1 dimension. Raw data were multiplied in both dimensions by a pure cosine-squared bell window function and Fouriertransformed to obtain $2048 \times 2048$ real data points. A polynomial baseline correction was applied in both directions. For data processing and spectral analysis, the standard Bruker software (XWinNMR 3.5) and XEASY program ${ }^{32}$ (ETH, Zurich) were used.

C. NOE Constraints. A total of 622,572 , and 685 NOESY cross-peaks were assigned in both dimensions for cyclo(87-99) $\mathrm{MBP}_{87-99}$, cyclo(87-99) [Ala $\left.{ }^{91,96}\right] \mathrm{MBP}_{87-99}$, and cyclo(87-99) $\left[\mathrm{Arg}^{91}, \mathrm{Ala}^{96}\right] \mathrm{MBP}_{87-99}$, respectively, in DMSO. The number of unique cross-peaks were 319,294 , and $353(25,23$, and 27 constraints per residue for cyclo(87-99) $\mathrm{MBP}_{87-99}$, cyclo(87-99) $\left[\mathrm{Ala}^{91,96}\right] \mathrm{MBP}_{87-99}$, and cyclo(87-99) $\left[\mathrm{Arg}^{91}, \mathrm{Ala}^{96}\right] \mathrm{MBP}_{87-99}$, respectively). Their intensities were converted into upper limit distances through CALIBA. ${ }^{33}$ Sequential constraints, number, and range of NOEs and chemical shift differences $\left(\left\{\left(\Delta \delta_{\mathrm{H \alpha}}\right)^{2}+\right.\right.$ $\left.\left.\left(\Delta \delta_{\mathrm{HN}}\right)^{2}\right\}^{1 / 2}\right)$ are illustrated in Figure 2 and Figure $\mathrm{S} 1$ in the Supporting Information.

D. Structure Calculations and Refinement. The NOE-derived structural information extracted from the analysis of NOESY spectra was acquired in DMSO- $d_{6}$ solutions under identical experimental conditions for all three peptides and was introduced to DYANA $^{34,35}$ software for structure calculation. The family ensemble of 20 best DYANA models for all three peptides (out of 400 calculated) in terms of target function $\left(<0.4 \AA^{2}\right)$ and NOE violations $(<0.2 \AA)$ was submitted to energy minimization through REM (AMBER 5.0 ${ }^{36}$, SANDER ${ }^{37}$ program). A force constant of 133.76 $\mathrm{kJ} \mathrm{mol}^{-1} \AA^{2}$ is applied for the distance constraints. MBP peptide models are illustrated in Figure 3 (figures are generated with MOLMOL $\left.{ }^{38}\right)$. Structural calculations have been performed on IBM RISC6000 and xw4100/xw4200 HP Linux workstations. The 20 model ensemble and the mean structures of (87-99) $\mathrm{MBP}_{87-99}$, analogues are illustrated at Figure 3.

E. Structure Preparation and Docking Simulation of the Peptides. The crystal structure coordinates of MHC were obtained from RCSB: PDB code 1ymm. All hetero atoms were removed. The program AutoDock $3.05^{39}$ was used for all docking calculations, and AutoDockTools was used for visual inspection of the docking results. MHC and the cyclo(87-99) $\mathrm{MBP}_{87-99}$ peptide were treated with the united-atom approximation by merging all nonpolar hydrogens. Kollman partial charges were assigned to all protein atoms. The grid maps were centered on the ligand's binding site, with $126 \times 106 \times 126$ grid-points of $0.3 \AA$ spacing. The Lamarckian genetic algorithm was employed with the parameters: a population size of 150 individuals, a maximum number of $1.5 \times$ $10^{6}$ energy evaluations, and a maximum number of 27000 generations, an elitism value of 1 , a mutation rate of 0.02 , and a crossover rate of $0.80 .{ }^{39}$ For all the calculations, 100 docking rounds were performed with step sizes of $0.2 \AA$ for translations and $5^{\circ}$ for orientations and torsions. Docked conformations were clustered with $0.5 \AA$ tolerance for the root-mean-square positional deviation. The protein-peptide complexes were visually inspected with $\mathrm{Au}$ toDockTools.

F. Docking Validation. The docking simulation treating the $\mathrm{MBP}_{85-99}$ peptide as a rigid molecule has been applied in order to explore whether the NMR-derived models of the cyclic $\mathrm{MBP}_{87-99}$ peptides retain the structure and physicochemical features that drive their binding to MHC and TCR receptors. In order to validate this approach, rigid docking simulations have also been applied for the complex of linear $\mathrm{MBP}_{85-98}$ with $\mathrm{MHC}$, for which the X-ray structure is available. Analysis of the simulation data and interatomic distances reveals that the placement of the linear $\mathrm{MBP}_{85-98}$ peptide is identical to that determined experimentally through X-ray crystallography (Figure S2, Supporting Information).

Acknowledgment. The present work is supported by the European Union and the Ministry of Development, Secretariat of Research and Technology of Greece (Grant PENED2003, 03ED827). EU-NMR (Contract RII3-026145) and CERM (Center of Magnetic Resonance, U of Florence) are also acknowledged for access to NMR instrumentation. The authors thank the Centre of Molecular Modelling of Cardiff University, Wales, U.K., for the provision of their IT facilities.

Supporting Information Available: ${ }^{1} \mathrm{H}$ and ${ }^{13} \mathrm{C}$ chemical shifts and statistical and analytical data. This material is available free of charge via the Internet at http://pubs.acs.org.

\section{References}

(1) Prat, E. T.; Martin, R. The immunopathogenesis of MS. J. Rehab. Res. Devel. 2002, 39, 187-200.

(2) Zamvil, S. S.; Steinman, L. The T lymphocyte in experimental allergic encephalomyelitis. Annu. Rev. Immunol. 1990, 8, 579-621.

(3) Ota, K.; Matsui, M.; Milford, E. L.; Mackin, G. A.; Weiner, H. L.; Hafler, D. A. T-cell recognition of an immunodominant myelin basic protein epitope in multiple sclerosis. Nature 1990, 346, 183-187.

(4) Valli. A.; Sette, A.; Kappos. L.; Oseroff, C.; Sidney, J.; Miescher, G.; Hochberger, M.; Albert, E. D.; Adorini, L. Binding of myelin basic protein peptides to human histocompatibility leukocyte antigen class II molecules and their recognition by $\mathrm{T}$ cells from multiple sclerosis patients. J. Clin. Invest. 1993, 91, 616-628.

(5) Martin, R.; Howell, M. D.; Jaraquemada, D.; Flerlage, M.; Richert, J.; Brostoff, S.; Long, E. O.; McFarlin, D. E.; McFarland, H. F. A myelin basic protein peptide is recognized by cytotoxic T cells in the context of four HLA-DR types associated with multiple sclerosis. J. Exp. Med. 1991, 173, 19-24.

(6) Mantzourani, E. D.; Mavromoustakos, T. M.; Platts, J. A.; Matsoukas, J. M.; Tselios, T. Structural requirements for binding of myelin basic protein (MBP) peptides to MHC II: Effects on immune regulation. Curr. Med. Chem. 2005, 12, 1521-1535.

(7) Rudolph, G.; M.; Wilson, I. A. The specificity of TCR/pMHC interaction. Curr. Opin. Immunol. 2002, 14, 1043-1052.

(8) Hare, B. J.; et al. Structure, specificity and CDR mobility of a class II restricted single-chain T-cell receptor. Nat. Struct. Biol. 1999, 6, $574-581$

(9) Willcox, B. E.; Gao, G. F.; Wyer, J. R.; Ladbury, J. E.; Bell, J. I.; Jakobsen, B. K.; van der Merwe, P. A. TCR binding to peptideMHC stabilizes a flexible recognition interface. Immunity 1999, 10, $357-365$.

(10) Smith, K. J.; Pyrdol, J.; Gauthier, L.; Wiley, D. C.; Wucherpfennig, K. W. Crystal structure of HLA-DR2 (DRA*0101, DRB1*1501) complexed with a peptide from human myelin basic protein. J. Exp. Med. 1998, 188 (8), 1511.

(11) Li, Y.; Huang, Y.; Lue, J.; Quandt, J. A.; Martin, R.; Mariuzza, R. A. Structure of a human autoimmune TCR bound to a myelin basic protein self-peptide and a multiple sclerosis-associated MHC class II molecule. EMBO J. 2005, 24, 2968-2979. 
(12) Tselios, T.; Daliani, I.; Deraos, S.; Thymianou, S.; Matsoukas, E.; Troganis, A.; Gerothanassis, I.; Mouzaki, A.; Mavromoustakos, T.; Probert, L.; Matsoukas, J. Treatment of experimental allergic encephalomyelitis (EAE) by a rationally designed cyclic analogue of myelin basic protein (MBP) epitope 72-85. Bioorg. Med. Chem. Lett. 2000, 10, 2713-2717.

(13) Matsoukas, J.; Apostolopoulos, V.; Kalbacher, H.; Papini, A. M.; Tselios, T.; Chatzantoni, K.; Biagioli, T.; Lolli, F.; Deraos, S.; Papathanassopoulos, P.; Troganis, A.; Mantzourani, E.; Mavromoustakos, T.; Mouzaki, A. Design and synthesis of a novel potent myelin basic protein epitope 87-99 cyclic analogue: enhanced stability and biological properties of mimics render them a potentially new class of immunomodulators. J. Med. Chem. 2005, 48, 14701480 .

(14) Tselios, T.; Apostolopoulos, V.; Daliani, I.; Deraos, S.; Grdadolnik, S.; Mavromoustakos, T.; Melachrinou, M.; Thymianou, S.; Probert, L.; Mouzaki, A.; Matsoukas, J. Antagonistic effects of human cyclic $\mathrm{MBP}_{87-99}$ altered peptide ligands in experimental allergic encephalomyelitis and human T-cell proliferation. J. Med. Chem. 2002, 45, 275-283.

(15) Davis, M. M.; Boniface, J. J.; Reich, Z.; Lyons, D.; Hampl, J.; Arden, B.; Chien, Y. Ligand recognition by $\alpha \beta$ T-cell receptors. Annu. Rev. Immunol. 1998, 16, 523-544.

(16) Hahn, M.; Nicholson, M. J.; Pyrdol, J.; Wucherpfennig, K. W. Unconventional topology of self peptide-major histocompatibility complex binding by a human autoimmune $\mathrm{T}$ cell receptor. Nat. Immunol. 2005, 6, 490-496.

(17) Wucherpfennig, K. W.; Sette, A.; Southwood, S. S.; Oseroff, S. C.; Matsui, M.; Strominger, J. L.; Haffler, D. A. Structural requirements for binding of an immunodominant myelin basic protein peptide to DR2 isotypes and for its recognition by human T cell clones. J. Exp. Med. 1994, 179, 279-290.

(18) Wucherpfennig, K. W.; Zhang, J.; Witek, C.; Matsui, M.; Modabber, Y.; Ota, K.; Hafler, D. A. Clonal expansion and persistence of human $\mathrm{T}$ cells specific for an immunodominant myelin basic protein peptide. J. Immunol. 1994, 152, 5581-5592.

(19) Garcia, K. C.; Degano, M.; Pease, L. R.; Huang, M.; Peterson, P. A.; Teyton, L.; Wilson, I. A. Structural basis of plasticity in T cell receptor recognition of a self peptide-MHC antigen. Science 1998, $279,1166-1172$

(20) Stewat-Jones, G. B.; McMichael, A. J.; Bell, J. I.; Stuart, D. I.; Jones, E. Y. A structural basis for immunodominant human T cell receptor recognition. Nat. Immunol. 2003, 8, 403-411.

(21) Hennecke, J.; Carfi, A.; Wiley, D. C. Structure of a covalently stabilized complex of a human $\alpha \beta$ T-cell receptor, influenza HA peptide and MHC class II molecule, HLA-DR1. EMBO J. 2000, 19, 5611-5624.

(22) Mantzourani, E. D.; Tselios, T. V.; Grdadolnik, S. G.; Platts, J. A.; Brancale, A.; Deraos, G.; Matsoukas, J. M.; Mavromoustakos, T. M. Comparison of proposed putative active conformations of linear altered peptide ligands of myelin basic protein epitope $87-99$ by spectroscopic and modelling studies: The role of position 91 and 96 in T-cell receptor activation. J. Med. Chem. 2006, 49, 66836691.

(23) Mantzourani, E. D.; Tselios, T. V.; Grdadolnik, S. G.; Brancale, A.; Platts, J. A.; Matsoukas, J. M.; Mavromoustakos, T. M. A putative bioactive conformation for the altered peptide ligand of myelin basic protein and inhibitor of experimental autoimmune encephalomyelitis
$\left[\mathrm{Arg}^{91}, \mathrm{Ala}^{96}\right] \mathrm{MBP}_{87-99}$. J. Mol. Graphics Model. 2006, 25, 1729.

(24) Falcone, M.; Bloom, B. R. A T helper cell 2 (Th2) immune response against non-self antigens modifies the cytokine profile of autoimmune $\mathrm{T}$ cells and protects against experimental allergic encephalomyelitis. J. Exp. Med. 1997, 185, 901-907.

(25) Chemical Computing Inc, 1010, Sherbrooke Street W, Suite 910, Montreal, Quebec, Canada 113A 2RF

(26) Vesterman, B.; Saulitis, J.; Betins, J.; Liepins, E.; Nikiforovich, G. V. Dynamic space structure of the Leu-enkephalin molecule in DMSO solution. Biochim. Biophys. Acta 1989, 998, 204.

(27) Braunschweiler, L.; Ernst, R. R. Coherence transfer by isotropic mixing: application to proton correlation spectroscopy. J. Magn. Reson. 1983, 53, 521-528.

(28) Bax, A.; Davis, D. G. MLEV-17-based two-dimensional homonuclear magnetization transfer spectroscopy. J. Magn. Reson. 1985, 65, 355360.

(29) Palmer, A. G., III; Cavanagh, J.; Wright, P. E.; Rance, M. Sensitivity improvement in proton-detected 2-dimensional heteronuclear correlation NMR spectroscopy. J. Magn. Reson. 1991, 93, 151-170.

(30) Marion, D.; Wüthrich, K. Application of phase sensitive twodimensional correlated spectroscopy (COSY) for measurements of ${ }^{1} \mathrm{H}-{ }^{1} \mathrm{H}$ spin-spin coupling constants in proteins. Biochem. Biophys. Res. Commun. 1983, 113, 967-974.

(31) Jeener, J.; Meier, B. H.; Bachmann, P.; Ernst R. R. Investigation of exchange processes by two-dimensional NMR spectroscopy. J. Chem. Phys. 1979, 71, 4546-4553.

(32) Eccles, C.; Güntert, P.; Billeter, M.; Wüthrich, K. Efficient analysis of protein 2D NMR spectra using the software package EASY. $J$. Biomol. NMR 1991, 1, 111-130.

(33) Güntert, P.; Braun, W.; Wüthrich, K. Efficient computation of threedimensional protein structures in solution from nuclear magnetic resonance data using the program DIANA and the supporting programs CALIBA, HABAS and GLOMSA. J. Mol. Biol. 1991, 217 , $517-530$.

(34) Güntert, P.; Mumenthaler, C.; Wüthrich, K. Torsion angle dynamics for NMR structure calculation with the new program DYANA. $J$. Mol. Biol. 1997, 273, 283-298.

(35) Wüthrich, K.; Billeter, M.; Brown, W. Pseudo-structures for the 20 common amino acids for use in studies of protein conformations by measurements of intramolecular proton-proton distance constraints with nuclear magnetic resonance. J. Mol. Biol. 1983, 169, 949-961.

(36) Pearlman, D. A.; Case, D. A.; Caldwell, J. W.; Ross, W. S Cheatham, T. E.; Ferguson, D. M.; Seibel, G. L.; Singh, U. C.; Weiner, P. K.; Kollman, P. A. AMBER 5.0; University of California, San Francisco, 1997.

(37) Pearlman, D. A.; Case, D. A.; Caldwell, G. C.; Siebel, G. L.; Singh, U. C.; Weiner, P.; Kollman, P. A. AMBER 4.0; University of California, San Francisco, 1991

(38) Koradi, R.; Billeter, M.; Wüthrich, K. MOLMOL: a program for display and analysis of macromolecular structures. J. Mol. Graphics 1996, 14, 51-55.

(39) Morris, G. M.; Goodsell, D. S.; Halliday, R. S.; Huey, R.; Hart, W. E.; Belew, R. K.; Olson, A. J. Automated docking using a Lamarckian genetic algorithm and an empirical binding free energy function. $J$. Comput. Chem. 1998, 19, 1639-1662.

JM070770M 